\title{
Corticosterone Promotes Scramble Competition Over Sibling Negotiation in Barn Owl Nestlings (Tyto alba)
}

\author{
Charlène A. Ruppli • Bettina Almasi • \\ Amélie N. Dreiss · Marine Battesti • \\ Lukas Jenni $\cdot$ Alexandre Roulin
}

Received: 26 July 2011/Accepted: 29 November 2011/Published online: 13 December 2011

(C) Springer Science+Business Media, LLC 2011

\begin{abstract}
In species with parental care, siblings compete for access to food resources. Typically, they vocally signal their level of need to each other and to parents, and jostle for the position in the nest where parents deliver food. Although food shortage and social interactions are stressful, little is known about the effect of stress on the way siblings resolve the conflict over how food is shared among them. Because glucocorticoid hormones mediate physiological and behavioral responses to stressors, we tested whether corticosterone, the main glucocorticoid in birds, modulates physical and vocal signaling used by barn owl siblings (Tyto alba) to compete for food. Although corticosterone-implanted (cort-) nestlings and placebo-nestlings
\end{abstract}

Charlène A. Ruppli and Bettina Almasi contributed equally to the work.

C. A. Ruppli $(\bowtie) \cdot$ A. N. Dreiss · M. Battesti · A. Roulin

Department of Ecology and Evolution, University of Lausanne,

1015 Lausanne, Switzerland

e-mail: Charlene.Ruppli@unil.ch

A. N. Dreiss

e-mail: Amelie.Dreiss@unil.ch

M. Battesti

e-mail: Marine.Battesti@legs.cnrs-gif.fr

A. Roulin

e-mail: Alexandre.Roulin@unil.ch

B. Almasi · L. Jenni

Swiss Ornithological Institute, 6204 Sempach, Switzerland

e-mail: Bettina.Almasi@vogelwarte.ch

L. Jenni

e-mail: Lukas.Jenni@vogelwarte.ch

M. Battesti

Université de Rennes 1, Campus de Beaulieu,

263 Avenue Général Leclerc, 35042 Rennes Cedex, France were similarly successful to monopolize food, they employed different behavioral strategies. Compared to placebo-nestlings, cort-individuals reduced the rate of vocally communicating with their siblings (but not with their parents) but were positioned closer to the nest-box entrance where parents predictably deliver food. Therefore, corticosterone induced nestlings to increase their effort in physical competition for the best nest position at the expense of investment in sib-sib communication without modifying vocal begging signals directed to parents. This suggests that in the barn owl stress alters nestlings' behavior and corticosterone could mediate the trade-off between scramble competition and vocal sib-sib communication. We conclude that stressful environments may prevent the evolution of sib-sib communication as a way to resolve family conflicts peacefully.

Keywords Begging - Corticosterone · Vocal signaling · Family conflict $\cdot$ Sib-sib communication .

Physical competition - Tyto alba

\section{Introduction}

Parents and offspring are in conflict over the amount and duration of parental care (Trivers 1974), each offspring demanding more resources than parents and siblings are willing to concede (Godfray 1995a). In altricial birds, nestlings commonly display conspicuous visual and vocal signals to solicit food from their parents (Leonard et al. 2003; Bulmer et al. 2008; Grim 2008) and compete physically by jockeying for the nest location where parents predictably deliver food resources (Teather 1992; Kacelnik et al. 1995; Nunez-de la Mora et al. 1996; Johnstone 2004; Drummond 2006; Tanner et al. 2008). As the pattern of 
within-brood food allocation depends on the complex interplay between the parental provisioning rules, offspring solicitation and sib-sib competition (Cotton et al. 1999; Roulin 2004; Smith et al. 2005), information about how siblings adjust their vocal and physical behaviors to one another is required (Smith and Montgomerie 1991; Roulin et al. 2000).

Siblings generally differ in physiological condition and body size. At a given feeding event, the expected payoff of obtaining food varies among siblings not only according to their level of need but also in relation to their resource holding potential. The benefit of consuming a prey item is greater for the neediest offspring, while the cost of food monopolization is lower for the individuals that are intrinsically more competitive (Godfray and Parker 1991; Godfray 1995b). Although food-deprived offspring commonly increase their investment in visual and vocal begging behaviors and/or physical competition (Smith and Montgomerie 1991; Cotton et al. 1996; Leonard et al. 2003; Smiseth et al. 2003; Porkert and Spinka 2006; Williams et al. 2008), the effectiveness of these behaviors in monopolizing food depends on their own competitive ability (Kacelnik et al. 1995; Price 1996). For instance, in bird species where eggs hatch asynchronously, which generates a pronounced within-brood age hierarchy among siblings, elder and thus stronger nestlings typically reduce effort invested in begging signals in favor of scramble competition (Kilner 1995; Lichtenstein and Sealy 1998; Ostreiher 2001; Rodriguez-Girones et al. 2001a; Leonard et al. 2003; Ploger and Medeiros 2004; but see Whittingham et al. 2003; Roulin 2004). This appears to be adaptive because to monopolize food resources physical competition can be more efficient than vocal begging (McRae et al. 1993; Kacelnik et al. 1995; Budden and Wright 2005; Tanner et al. 2008). Poorly competitive nestlings (e.g. juniors) that are barely able to get access to the best nest position may compensate by producing more intense begging calls to attract the attention of their parents and thereby influence within-brood parental food allocation and induce an increase in parental feeding rate (Cotton et al. 1999; Smiseth and Amundsen 2002; Roulin 2004). Because siblings experience different cost-benefit ratios in investing in signaling and scramble competition, they are likely to employ different behavioral strategies to monopolize food resources (Smiseth and Amundsen 2002).

The behaviors each single nestling uses to get access to food resources depends on nestlings' resource holding potential, hunger level and body condition, which are all tightly linked to their physiological state. In particular, glucocorticoids may help nestlings to regulate their behavior in relation to their own need (Schwabl and Lipar 2002). When experiencing a temporary stressful situation, for instance due to food shortages or immune challenges, nestling birds release corticosterone into the blood to adopt adequate behavioral and physiological responses (Nunezde la Mora et al. 1996; Kitaysky et al. 1999; Sockman and Schwabl 2001). Siblings often differ in their adrenocortical stress response, higher levels of baseline and stress-induced circulating corticosterone often being found in older/dominant nestlings (Schwabl 1999; Creel 2001; Love et al. 2003; Blas et al. 2006; Müller et al. 2010). Interestingly, an experimental manipulation of circulating corticosterone levels induced more intense begging behaviors in the presence of parents in both the black-legged kittiwake (Rissa tridactyla; Kitaysky et al. 2001) and house sparrow (Passer domesticus; Loiseau et al. 2008). While in kittiwakes experimental elevation of corticosterone levels did not modify the rate of sib-sib agonistic interaction, in bluefooted boobies (Sula nebouxii) it induced subordinate nestlings to increase spontaneous submissiveness towards their non-implanted dominant brood mates, though the authors could not disentangle the exact mutual influence of siblings on each other (Vallarino et al. 2006). The main stress hormone, corticosterone, thus appears to play a major role in how nestling birds adjust the level of vocal signaling and physical competitive behaviors. Studying this role is likely to provide key insights into how environmental and social stressful factors influence sib-sib and parent-offspring interactions.

In the present study, we investigated whether corticosterone modulates investment in vocal signaling and physical competition. To this end, we experimentally manipulated corticosterone levels in barn owl nestlings (Tyto alba). In the prolonged absence of parents, siblings communicate vocally among each other to indicate their motivation to compete for the indivisible food item next delivered by a parent, a process referred to as 'sibling negotiation', and they barely show physical aggressiveness. The hungriest individual vocalizes at a high rate, which deters its siblings from begging and competing once parents are back at the nest with a food item (Roulin 2004). In a free-living barn owl population, we created 34 two-chick broods by temporarily removing nestlings from nests except two randomly chosen individuals. Two or five days earlier we implanted them with either a corticosteronereleasing pellet or a placebo-pellet, a manipulation that modifies the level of circulating corticosterone within the natural range (Müller et al. 2009). We recorded the vocal behavior of the two individuals both in the absence of the parents (i.e. negotiation), during the 15 min preceding their arrival with the first prey item of the night, and in their presence (i.e. begging). We also recorded the position of the two siblings relative to the nest-box entrance where parents predictably deliver food, and which of the two individual obtained the prey item. As shown in a previous study, an experimental increase in corticosterone levels 
impairs humoral immunity, resistance to oxidative stress and growth rate (Stier et al. 2009). Assuming that jostling for position, vocal negotiation and begging entail substantial costs (Leech and Leonard 1996; Rodriguez-Girones et al. 2001b; Roulin 2001b; Bize and Roulin 2006; Moreno-Rueda 2010; but see Moreno-Rueda 2007), the manipulation of corticosterone levels may differentially affect these behaviors.

\section{Methods}

\section{Study Species}

The study was carried out in 2004 and 2005 using freeliving barn owls breeding in nest-boxes $(100 \times 60 \times$ $50 \mathrm{~cm}$ ) located in western Switzerland $\left(46^{\circ} 49^{\prime} \mathrm{N} / 06^{\circ} 56^{\prime} \mathrm{E}\right)$. The two to eleven eggs hatch every 2.5 days since incubation starts as soon as the first egg has been laid. A pronounced within-brood age hierarchy is thus established among the siblings. Until nestlings are 3 weeks old, the female stays at the nest to provision offspring with small mammals brought by the father. Afterwards, the mother delivers one-third of the prey items to the offspring, each item being consumed by a single offspring. We thus carried out the experiments when nestlings were old enough to be thermo-independent so that when we manipulated nestlings during the daylight hours, parents were naturally sleeping outside their nest-box in another barn as our observations demonstrated. Until fledging, occurring at ca. 55 days of age, siblings compete for food vocally and physically without, however, being overly aggressive. Previous studies showed that in broods of two nestlings the individual that obtains the first prey item of the night produces on average 7.7 calls/min before a parent arrives at the nest and 45.8 in its presence; its sibling produces 3.9 calls $/ \mathrm{min}$ in the absence and 30.4 in the presence of parents (Roulin 2001a). Nestling age was estimated shortly after hatching by measuring the length of the left flattened wing from the bird's wrist to the tip of the longest primary (Roulin 2004). Nestling sex was determined using molecular markers (Py et al. 2006).

\section{Experimental Manipulation of Corticosterone Level}

To study the effect of corticosterone on nestlings' behavior, we considered 19 nests in 2004 and 15 nests in 2005. In each nest in 2004 we implanted two individuals with a $15 \mathrm{mg}$ self-degradable corticosterone-releasing pellet (cat \# G-111, Innovative Research of America (Sarasota, FL, USA)) and two siblings with a placebo pellet. The pellets were placed under the skin of the flank above the knee through a small incision (see Müller et al. (2009) for further details on the implantation procedure). In 2005 we implanted one individual per nest with a similar corticosterone-releasing pellet and one sibling with a placebo pellet. In both years, at the day of implantation owlets implanted with a corticosterone-releasing pellet (hereafter 'cort-nestlings') and owlets implanted with a placebopellet (hereafter 'placebo-nestlings') were similarly aged (2004: $30.0 \pm 0.7$ days vs. $31.0 \pm 0.9$ days; paired $t$ test, $P=0.30 ; \quad 2005: 31.0 \pm 0.9$ days vs. $30.0 \pm 1.4$ days; $P=0.70)$ and had a similar weight (2004: $342 \pm 10 \mathrm{~g}$ vs. $356 \pm 9 \mathrm{~g} ; P=0.30 ; 2005: 318 \pm 6 \mathrm{~g}$ vs. $327 \pm 15 \mathrm{~g}$; $P=0.40)$ on average. We did not implant younger nestmates (aged $26.0 \pm 2.3$ days) because the corticosteronereleasing pellets were designed for older individuals. We recorded the behavior of one cort- and one placeboimplanted nestling in each nest. To do so, we removed all owlets from their nest-box except one cort- and one placebo-individual among the four implanted individuals in each nest in 2004, and all but the two implanted individuals in 2005. Using an infrared camera with a microphone we recorded the two siblings ringed on a different leg for individual recognition from 19:00 to 24:00. At 24:00 we brought back the removed individuals that were previously placed in a large ventilated plastic box at some distance from their nest-box. This experimental design was already successfully used in a previous study (Roulin et al. 2000; Roulin 2004). We video-recorded implanted nestlings fivedays post-implantation in 2004, with placebo nestlings being significantly heavier than their cort-sibling $(359 \pm 8$ vs. $325 \pm 9, P=0.02$ ) but similarly aged (paired $t$ test, $P$ value $=0.71)$. We chose to record five-days post implantation since the pellets were designed by Innovative Research of America to release corticosterone during 6 days. To confirm this statement, we collected blood and analyzed it in the autumn 2004. It appeared that a measurable increase in corticosterone occurred only during the first 3 days post-implantation (Müller et al. 2009). For this reason, we changed the experimental design in 2005 and recorded nestlings' behavior 2 days post-implantation and not 5 days as in 2004. In total, we implanted with a corticosterone-releasing pellet as often the younger individual, so-called junior, as the older, so-called senior ( $n=18$ vs. 16), and as often males as females (each time 17). In 2005 , Cort- and placebo-siblings did not differ in age and body mass on the day when we recorded their behavior (paired $t$ tests, both $P>0.19$ ).

We measured baseline total corticosterone levels in implanted nestlings by collecting blood samples at the day of implantation, 2, 6 and 20 days after implantation in 2004, and at the day of implantation, 3 and 20 days after implantation in 2005. To determine baseline corticosterone levels we collected blood samples within $3 \mathrm{~min}$ after having opened the nest box (Romero and Reed 2005). 
Stress-induced corticosterone levels were monitored 2 or 3 days post-implantation by collecting a blood sample on average $27 \pm 0.75 \mathrm{~min}$ after opening the nest-box. The time until we collected the stress-induced corticosterone samples did not differ between the two treatments (paired $t$ test: $P>0.40$ ). Total plasma corticosterone concentration was measured with an enzyme immunoassay (Munro and Stabenfeldt 1984; Almasi et al. 2009). Before implantation, there was no difference in baseline corticosterone between placebo- and cort-nestlings in both years (Table 1). Two days after implantation cort-nestlings had significantly higher baseline corticosterone levels than placebo-nestlings (Table 1). Three, six and twenty days after implantation baseline corticosterone levels did not differ anymore between the two treatment groups (Table 1). Two and three days post-implantation the stress-induced corticosterone level of cort-nestlings was significantly lower compared to placebo-nestlings (Table 1). Thus, when we video-recorded nestlings during the second night after implantation in 2005, our experimental corticosterone treatment was likely to still have an effect on the hypothalamic-pituitaryadrenal (HPA)-axis. It was also likely the case during the fifth night after implantation in 2004 since cort-nestlings were heavier than their placebo siblings and lasting detrimental effects on body conditions were still observed several weeks later (Almasi et al. submitted).

\section{Assessment of Nestling Behaviors}

On the video footage we analyzed nestling behavior in the absence of parents (i.e. during the so-called negotiation period) during the first $14 \mathrm{~min}$ of the $15 \mathrm{~min}$ preceding the first parental visit of the night; they always brought a prey item at this visit. During this period we determined the mean negotiation call rate per individual (number of calls per minute) by counting negotiation calls produced by the placebo- and cort-siblings blindly with respect to treatment. The relative position of each owlet in the nest-box during the 14 min of observation (hereafter referred to as 'Position in parents' absence' was defined as the amount of time it stood closer (but not at a similar distance) to the nest-box entrance than its sibling over the total amount of time during which one individual was closer (but not at a similar distance) to the nest-box entrance than its sibling. We analyzed 28 broods for this variable because in 6 of the 34 broods the two siblings stood at the same distance to the entrance during the 15 min preceding the arrival of a parent.

We determined the mean begging call rate per individual (number of calls per minute) in the presence of parents by counting calls between the time when nestlings detected the incoming parent and the time when this parent gave its prey item to one of the two nestlings; as soon as a parent is detected the offspring change their behavior by being more vocal and approaching the nest entrance. Because the time span during which calls were counted varied from one nest to another (mean \pm SE: $14.1 \pm 3.7 \mathrm{~s}$ ), we considered only calls produced during the first $5 \mathrm{~s}$ after the parent was detected. We analyzed 19 broods out of 34 for this variable because in 15 broods the prey item was consumed within these $5 \mathrm{~s}$. Calls were correctly assigned to one of the two siblings because nestlings open their bill while calling, and calls of different individuals are easily distinguishable by the human ear (pers. obs.). Finally, we determined the relative position of the two siblings at the exact moment when the incoming parent was detected (hereafter referred to as 'Position in parents' presence'). We assigned score 1 to the cort-individual when it was closer to the nest-box entrance than its placebo-sibling, score 0 when it was at the same distance, and score -1 when it was further away from

Table 1 Baseline and stress-induced corticosterone levels and body mass in corticosterone- and placebo-implanted barn owl nestlings in 2004 and 2005

\begin{tabular}{|c|c|c|c|c|c|c|c|c|c|c|}
\hline \multirow[t]{2}{*}{ Year } & \multirow[t]{2}{*}{ Day } & \multicolumn{2}{|c|}{ Baseline corticosterone (ng/ml) } & \multirow{2}{*}{$\begin{array}{l}\text { Welch } \\
t \text { test }\end{array}$} & \multicolumn{2}{|c|}{ Stress-induced corticosterone $(\mathrm{ng} / \mathrm{ml})$} & \multirow[t]{2}{*}{ Welch $t$ test } & \multicolumn{2}{|l|}{ Body mass (g) } & \multirow{2}{*}{$\begin{array}{l}\text { Welch } \\
t \text { test }\end{array}$} \\
\hline & & Cort & Placebo & & Cort & Placebo & & Cort & Placebo & \\
\hline \multirow[t]{5}{*}{2004} & 0 & $8.8 \pm 1.3(6)$ & $10.9 \pm 2.3(9)$ & 0.4 & & & & $344 \pm 6(19)$ & $349 \pm 10(19)$ & 0.7 \\
\hline & 2 & $26.0 \pm 3.1(10)$ & $9.5 \pm 1.6(8)$ & $<0.001$ & $28.1 \pm 3.2(14)$ & $50.1 \pm 5.8(14)$ & $<0.001$ & $320 \pm 6(19)$ & $341 \pm 7$ (19) & 0.03 \\
\hline & 3 & & & & & & & & & \\
\hline & 6 & $12.6 \pm 3.0(11)$ & $14.9 \pm 2.9(9)$ & 0.6 & & & & $327 \pm 6(19)$ & $357 \pm 8(19)$ & 0.02 \\
\hline & 20 & $12.8 \pm 2.1$ & $11.4 \pm 1.8(8)$ & 0.6 & $55.2 \pm 6.6(11)$ & $69.5 \pm 5.0(11)$ & 0.1 & $353 \pm 6(19)$ & $356 \pm 4$ (19) & 0.6 \\
\hline \multirow[t]{5}{*}{2005} & 0 & $8.5 \pm 1.4(14)$ & $8.5 \pm 0.9(13)$ & 0.1 & $58.1 \pm 9.0(10)$ & $68.6 \pm 14.3(10)$ & 0.5 & $313 \pm 8(15)$ & $327 \pm 14(15)$ & 0.4 \\
\hline & 2 & & & & & & & & & \\
\hline & 3 & $9.2 \pm 1.4(15)$ & $11.5 \pm 2.0(9)$ & 0.4 & $39.8 \pm 12.1(12)$ & $65.7 \pm 8.7(12)$ & 0.02 & $321 \pm 4(15)$ & $333 \pm 6(15)$ & 0.1 \\
\hline & 6 & & & & & & & & & \\
\hline & 20 & $7.8 \pm 0.9(15)$ & $8.3 \pm 2.6(10)$ & 0.8 & & & & $334 \pm 10(15)$ & $381 \pm 9(15)$ & 0.002 \\
\hline
\end{tabular}

Data were collected on the day of implantation (day 0) and 2, 3, 6 and 20 days post implantation. $P$ values for two-tailed Welch $t$ tests are presented. Sample sizes are given in brackets 
the nest-box entrance than its placebo-sibling. We also noted the identity of the nestling that obtained the first food item of the night, and in 31 broods we could determine the identity of the individual that ingested it. In all cases, the individual that ate the prey item was also the one that obtained it from its parent.

\section{Statistical Procedure}

In all our analyses we pooled the data collected in 2004 and 2005 because cort- and placebo-nestlings displayed the same trends in all behaviors in both years despite that they were recorded at different times after implantation. Nonetheless, we controlled for potential biases due to the year at which we implanted them by including the variable 'year' in our analyses (see further). In a first step, we investigated how often the placebo- and the cort-nestlings monopolized the first delivered prey item of the night. We also examined whether call rates and relative positions both in the absence of parents and at their arrival were associated with the probability that the individuals monopolized the prey item, by performing a nested generalized binomial mixed effect model (GLMM) with prey monopolization (1 if the individual got the prey, 0 if it did not get the prey item) as response variable. Since we had fewer data on behaviors recorded in the presence than in the absence of parents, we performed two separate analyses for the situation when nestlings were negotiating and when they were begging food from their parents. In both models, we included site identity as random intercept to control for the dependency of the data collected in the two siblings per nest. Fixed effects comprised year, nestlings' sex, treatment (placebovs. cort-), negotiation (or begging) call rate and relative position in the nest in the absence (or at the arrival) of parents (i.e. position in parents' absence/presence). We accounted for nestlings' seniority (junior or senior) only in the model on negotiation behaviors since the model on begging behaviors did not converge when we included it and seniors and juniors displayed similar trends anyway. In both models, we also included the interaction between the corticosterone treatment and year, and the interactions between treatment and negotiation (or begging) call rate, and between treatment and relative position in the nest while negotiating (or begging). These interactions were implemented to examine whether the effect of treatment varied across the 2 years and whether the influence of nestlings' behaviors on the success in prey monopolization depended on treatment. All fixed effects were tested using a 'Monte Carlo simulation' approach after Faraway (2006). Thereby, the distribution of the likelihood ratio for comparing an alternative model (containing a given term) with a null model (model without this term) was approximated using Monte Carlo simulation. We simulated 200 times a set of response values from the null model and calculated the likelihood ratio between the alternative and the null model for each set of simulated response values. From these 200 likelihood ratios an approximation of the distribution of the likelihood ratio was obtained and used instead of a Chi-square distribution to obtain the $P$ value (Faraway 2006). Non-significant interactions were removed from the model before testing main effects independently from one another.

In a second step, we investigated whether negotiation and begging call rates, as well as the relative position in the nest in the absence of parents and at their arrival, were affected by treatment. For negotiation and begging call rates and the relative position in the absence of parents, we ran a nested linear mixed-effect model with normal distribution for each behavior with nestlings' behavior as the response variable and site identity as random intercept to control for the dependency of the data collected in the two siblings per nest. We included year, nestlings' seniority and sex, treatment and the interaction between treatment and year as covariates. The model with the negotiation call rate as dependent variable also comprised the relative position in the absence of parents and its interaction with treatment, and vice versa for the model of relative position in the absence of parents; the model of begging call rate comprised both negotiation call rate and relative position in the absence of parents plus their interaction with treatment. All fixed effects were tested using a similar approach as described above except that we could run 500 simulations since it was less time consuming than to simulate in a binomial-model. Since position in parents' absence varied between 0 and $100 \%$ of time spent in front of the sibling relative to the nest entrance, and hence corresponded to a proportion, we arcsine-root transformed this variable to obtain normally distributed residuals.

Because of the way we measured the relative position of cort-individuals at the arrival of parents (position in relation to the nest entrance and to the location of their placebo-sibling), we did not run mixed effects models on this variable. We tested the effect of treatment on the position of cort-nestlings with a Wilcoxon signed rank test; we did not perform a paired test because there was only one value per nest (either the cort-individual was in front, behind or at the same distance to the nest entrance as its placebo sibling).

All statistical tests were done using the software package R version 2.12.1 (R Development Core Team 2010), with libraries lme4 for mixed-effect models and arm for the simulations. $P$ values and estimates obtained from simulations were consistent with those of non-reduced models, indicating that our results were not biased by an inflated type-I error due to multiple testing on our small sample sizes. Means and estimates are quoted $\pm \mathrm{SE}$ if not 
indicated otherwise. $P$ values $\leq 0.05$ were considered as significant.

\section{Ethical Note}

The study was carried out with the agreement of the 'Service Vétérinaire du canton de Vaud' (authorization no1736). The manipulation of corticosterone as well as implanting a pellet (corticosterone-releasing or placebo) did not alter nestlings' fledging success since $94 \%$ of all implanted nestlings in 2004 and 2005 survived until fledging (unpubl. data).

\section{Results}

Effects of Corticosterone and Nestlings' Behaviors on Prey Monopolization

Binomial mixed effect models tested the effects of the corticosterone treatment and nestlings' behaviors in the absence of parents (Table 2a) and at their arrival (Table $2 b$ ) on the success in prey monopolization. Nestlings' success in obtaining the first prey item of the night brought by the parents did not depend on treatment, year, or their interaction, and neither on sex and seniority. Indeed, a similar number of cort- and placebo-nestlings (18 vs.16), females and males (16 vs. 18), and juniors and seniors (20 vs. 14) monopolized the first prey item of the night, (all $P \geq 0.1$, Table 2a, b). Prey obtaining was associated with nestling behaviors in the absence of parents in a similar way in placebo- and cort-individuals because both interactions between behaviors and treatment were not significant (both $P \geq 0.8$, Table $2 \mathrm{a}$ ); higher negotiation call rate (estimate: $0.20 \pm 0.08$ ) and proportion of time spent in front of their sibling relative to the nest hole before parents' arrival (estimate for 'Position in parents' absence': $2.2 \pm 0.9)$ were associated with a higher probability of obtaining the prey item (Table 2a, Fig. 1). The probability that a nestling monopolized the prey item was $60 \%$ if it stayed always closer to the nest-box entrance than its sibling and $14 \%$ if it stayed always behind its sibling.

By contrast to behaviors in the absence of parents, nestlings' call rate and relative position in the presence of parents did not significantly affect their chance of being fed (both $P=0.1$, Table 2b). However, the non-significance of begging call rate on the success in prey monopolization may be due to a lack of statistical power, since both placebo- and cort-nestlings begged at a higher rate just before monopolizing the first prey item than when the item was monopolized by their sibling (Student's $t$ tests, both $P<0.05$, Fig. 1).
Table 2 Binomial mixed-effect models on prey monopolization in the barn owl with nestlings' call rate and relative position (A) in the absence of parents and (B) in the presence of parents, as covariates

Prey monopolization

\begin{tabular}{lccl}
\hline Fixed effects & $d f$ & LR & $P_{\text {boot }}$ \\
\hline A: behaviors in parents' absence & & & \\
Year & 1 & 0.0 & 0.9 \\
Nestling seniority & 1 & 0.6 & 0.5 \\
Nestling sex & 1 & 0.4 & 0.6 \\
Cort treatment & 1 & 3.0 & 0.1 \\
Negotiation call rate & 1 & $\mathbf{1 0 . 2}$ & $\mathbf{0 . 0 0 5}$ \\
Position in parents' absence & 1 & $\mathbf{7 . 4}$ & $\mathbf{0 . 0 2}$ \\
Cort treatment $\times$ year & 1 & 0.8 & 0.4 \\
Cort treatment $\times$ negotiation call rate & 1 & 0.0 & 0.9 \\
Cort treatment $\times$ position in parents' absence & 1 & 0.1 & 0.8 \\
B: behaviors in parents' presence & & & \\
Year & 1 & 0.0 & 0.9 \\
Nestling seniority & - & - & - \\
Nestling sex & 1 & 1.4 & 0.3 \\
Cort treatment & 1 & 0.9 & 0.4 \\
Begging call rate & 1 & 4.4 & 0.1 \\
Position in parents' presence & 2 & 5.9 & 0.1 \\
Cort treatment $\times$ year & 1 & 0.0 & 0.9 \\
Cort treatment $\times$ begging call rate & 1 & 0.1 & 0.7 \\
Cort treatment $\times$ position in parents' presence & 2 & 3.6 & 0.2 \\
\hline
\end{tabular}

Site identity was included as a random intercept. Analyses are based on (A) 56 individuals from 28 sites and (B) 38 individuals from 19 sites

All these findings were robust despite the dependency of behaviors on treatment. Indeed, fitting treatment and behaviors as independent variables in separated analyses gave similar results (GLMM with prey monopolization as dependent variable and with treatment as fixed effect: $d f=1, \mathrm{LR}=0.9, P_{\text {boot }}=0.4 ;$ GLMM with negotiation behaviors as fixed effects: negotiation call rate: $d f=1$, $\mathrm{LR}=7.3, \quad P_{\text {boot }}=0.03$, position in parents' absence: $d f=1, \mathrm{LR}=10.5, P_{\text {boot }}=0.02 ;$ GLMM with begging behaviors as fixed effects: begging call rate: $d f=1$, $\mathrm{LR}=4.4, P_{\mathrm{boot}}=0.06$; position in parents' presence: $\left.d f=2, \mathrm{LR}=6.5, P_{\text {boot }}=0.06\right)$.

\section{Effect of Corticosterone on Behaviors and Mutual Influences Between Behaviors}

Linear mixed-effect models tested whether negotiation call rate, relative position in the nest before the arrival of parents, and begging call rate were affected by treatment and how these behaviors influenced each other (Table 3). Nestlings' negotiation and begging call rates and relative position in the absence of parents were not affected by the 
Fig. 1 Mean negotiation and begging call rates (left) of barn owl nestlings and proportion of time they spent closer to the nest entrance than their siblings in the absence of parents (right) according to whether they obtained the next prey item delivered by their parent or not. Above and below the dotted line, nestlings spent respectively more time in front of or behind their sibling. Bars represent means \pm standard errors
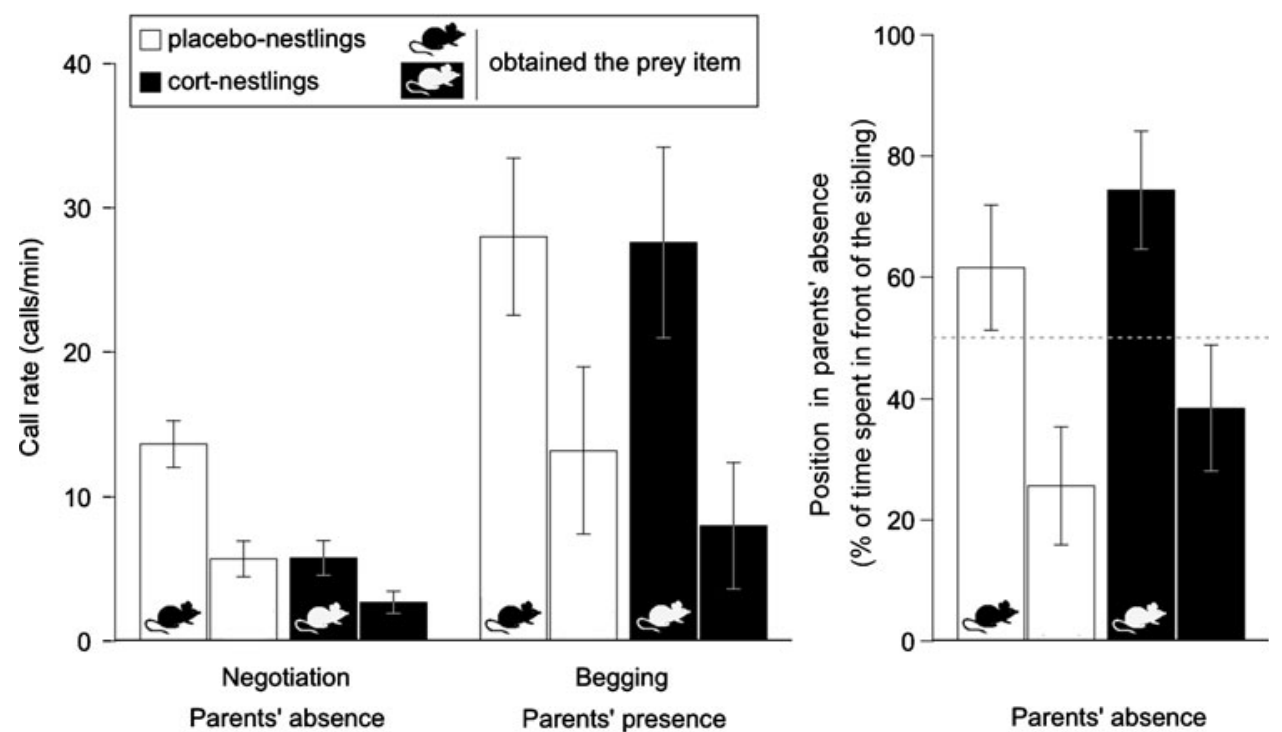

Table 3 Mixed-effect models on negotiation call rate, relative amount of time spent closer to the nest entrance (position) in the absence of parents (arcsine-root transformed) and begging call rate

\begin{tabular}{|c|c|c|c|c|c|c|c|c|c|}
\hline \multirow[b]{2}{*}{ Fixed effects } & \multicolumn{3}{|c|}{ Negotiation call rate } & \multicolumn{3}{|c|}{ Position in parents' absence } & \multicolumn{3}{|c|}{ Begging call rate } \\
\hline & $d f$ & LR & $P_{\text {boot }}$ & $d f$ & LR & $P_{\text {boot }}$ & $d f$ & LR & $P_{\text {boot }}$ \\
\hline Year & 1 & 0.3 & 0.6 & 1 & 0.1 & 0.8 & 1 & 0.05 & 0.8 \\
\hline Seniority & 1 & 0.1 & 0.8 & 1 & 0.2 & 0.7 & 1 & 0.1 & 0.8 \\
\hline Sex & 1 & 1.4 & 0.3 & 1 & 1.1 & 0.4 & 1 & 5.2 & 0.05 \\
\hline Cort treatment & 1 & 12.0 & 0.002 & 1 & 6.5 & 0.02 & 1 & 0.01 & 0.9 \\
\hline Negotiation call rate & - & - & & 1 & 5.8 & 0.04 & 1 & 4.7 & 0.07 \\
\hline Position in parents' absence & 1 & 5.1 & 0.04 & - & - & & 1 & 6.2 & 0.04 \\
\hline Cort treatment $\times$ year & 1 & 0.5 & 0.5 & 1 & 0.8 & 0.4 & 1 & 0.02 & 0.9 \\
\hline Cort treatment $\times$ negotiation call rate & - & - & & 1 & 0.04 & 0.9 & 1 & 0.5 & 0.6 \\
\hline Cort treatment $\times$ position in parents' absence & 1 & 1.4 & 0.3 & - & - & & 1 & 0.5 & 0.6 \\
\hline
\end{tabular}

In each model, site identity was included as a random intercept. Analyses are based on 56 individuals from 28 sites for negotiation call rate and position in parents' absence and on 32 individuals from 16 sites for begging call rate. Dashes correspond to the fixed effects that were not included in the models

year of experiment or by seniority (all $P \geq 0.6$ ). Sex did not influence the behaviors either, except for begging call rate (males produced $13.3 \pm 5.6$ more calls/min in presence of parents than females, $P=0.05$ ).

In the absence of parents, treatment had a significant effect on both negotiation call rate and relative position (Table 3), which was consistent across the 2 years of experimentation (interactions 'Cort treatment $\times$ Year', both $P \geq 0.4$ ). In both placebo- and cort-nestlings, the level of negotiation and the relative amount of time spent in front of their sibling were positively correlated (negotiation call rate as the response variable, estimate for position: $4.2 \pm 1.8$ calls $/ \mathrm{min}$; relative position in the absence of parents as the response variable, estimate for negotiation call rate: $3.3 \pm 1.3$, interactions 'Cort treatment $\times$ Position in parents' absence' and 'Cort treatment $\times$ Negotiation call rate': both $P \geq 0.3$ ), as illustrated in Fig. 2. Additionally, placebo-individuals produced significantly more calls on average than their cort-sibling (negotiation call rate as the response variable, estimate for treatment (placebo vs. cort): $5.6 \pm 1.5$ calls $/ \mathrm{min}$ ), whereas cort-individuals spent significantly more time, ca. $18 \%$ (7-33\%), close to the nest-box entrance than placebonestlings (Table 3, relative position in the absence of parents as the response variable, estimate for treatment (placebo vs. cort): $-0.4 \pm 0.2$ ).

Nestlings that spent more time close to the nest entrance in the absence of parents begged at a higher rate at the arrival of a parent (Table 3, begging call rate as the response variable, estimate for 'Position in parents' absence': $19.5 \pm 7.5 \mathrm{calls} / \mathrm{min}$ ). In addition, the more nestlings had negotiated the more they tended to beg at the parents, but this relationship remained marginal (begging call rate as the response variable, estimate for negotiation 


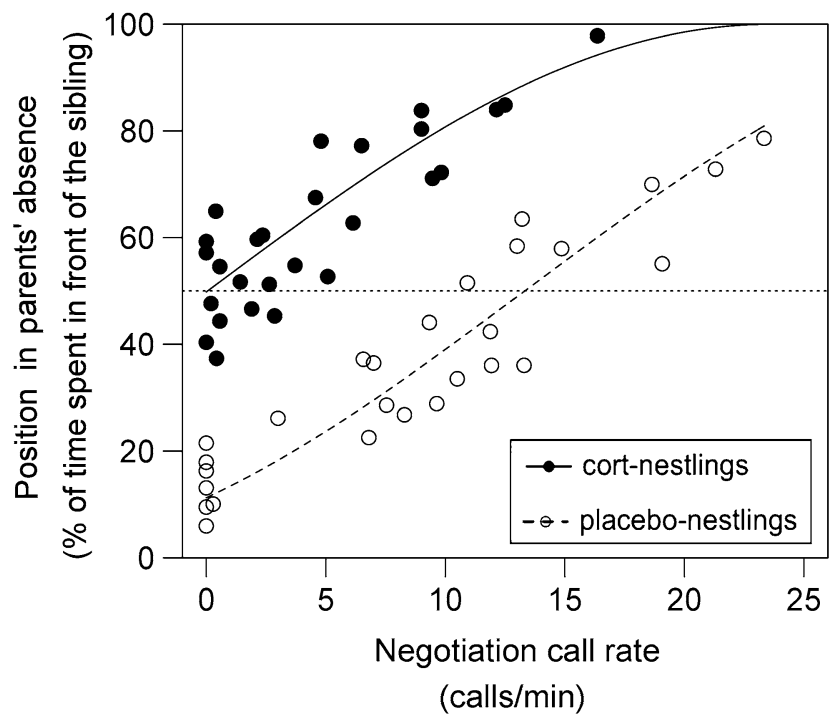

Fig. 2 Amount of time that barn owl nestlings spent closer to the nest entrance than their siblings (position in the absence of parents) in relation to negotiation call rate before the first feeding of the night. Dots and curves represent back-transformed predicted values and curves from linear mixed model of Table 3 for position in the absence of parents in relation to negotiation call rate in cort-implanted (black dots, plain line) and placebo nestlings (white dots, dashed line) respectively ( $n=28$ broods). Above and below the dotted line, nestlings spent respectively more time in front of or behind their sibling

call rate: $1.1 \pm 0.5$ calls $/ \mathrm{min}, P=0.07)$. These trends did not differ between placebo- and cort-individuals ('Cort treatment $\times$ Position in parents' absence' and 'Cort treatment $\times$ Negotiation call rate', both $P=0.6$ ). However, treatment had no effect on nestlings' begging call rate at the parents' visit, whatever the year of experimentation ('Cort treatment' and 'Cort treatment $\times$ Year', both $P=0.9$ ). Cort-nestlings stood as often closer to the nest entrance as placebo-nestlings during parents' presence (relative position of the cort-individual as dependent variable, Wilcoxon signed rank test: $n=32, \mathrm{~V}=0.56, P=0.43$ ).

\section{Discussion}

In nestling barn owls, we investigated whether the hormone that mediates physiological and behavioral responses to stressors, i.e. corticosterone, regulates investment in the level of vocal signaling to both siblings (i.e. negotiation) and parents (i.e. begging), and the frequency with which siblings stand close to the nest-box entrance where parents predictably arrive. We also examined whether this hormone influences the probability of monopolizing food. Our main finding is that nestlings implanted with a corticosterone-releasing pellet, despite monopolizing the first prey item of the night as often as their placebo-siblings and maintaining an equal begging effort at the parent's arrival, reduced investment in the level of sib-sib communication (i.e. they vocalized at a lower rate in the absence of parents) and spent more time closer to the nest entrance where parents predictably deliver food before the parent's visit (Fig. 1). Thus, corticosterone induced nestlings to modify their strategies to compete over food resources delivered by their parents. Indeed, prey monopolization was enhanced by higher effort both in negotiating with siblings, in begging towards the parents, and in standing closer to the nest entrance before parents' visit. Apparently, the strategies employed by cort- and placebo-nestlings were equally successful, since they monopolized food as often. Our results suggest that corticosterone induces nestlings to switch from vocal to physical competition in the absence of parents but not in their presence. This is in line with previous theoretical and empirical work showing that food supply (i.e. a potential cause of stress) affects sibling negotiation to a larger extent than begging behavior (Roulin 2001a; Johnstone and Roulin 2003).

\section{Effect of Corticosterone on Sib-Sib Interactions}

Barn owl nestlings implanted with a corticosteronereleasing pellet showed an impaired body mass gain (Table 1) and reduced humoral immunity and resistance to oxidative stress (Stier et al. 2009). Thus, cort-nestlings were in a stressful state implying that the benefit of monopolizing a food item was probably higher for them than for placebo-nestlings, while the costs per unit of investment in signaling and sibling competition were probably more detrimental to cort- than placebo-nestlings. Because cort-nestlings consumed the first prey item delivered of the night as often as placebo-nestlings, we conclude that corticosterone prevented nestlings to invest extra effort in sibling competition to an extent that would have allowed them to compensate for the negative effects of corticosterone by eating more food. Indeed, they did not beg more frequently than their sibling and they refrained from negotiating.

In the barn owl, the nestling that begs at the highest rate in the presence of parents has a higher probability of monopolizing the delivered food item, and the effort an individual invests in begging depends on complex sib-sib interactions taking place in the absence of parents. A nestling positioned close to the nest entrance will induce its siblings to reduce investment in sibling negotiation. Additionally, an individual that negotiates at a higher level than its sibling deters them to beg intensely for food from their parents (Dreiss et al. 2010). Therefore, a nestling can employ two non-mutually exclusive strategies to influence its siblings to refrain from begging: (1) it stands close to the 
nest entrance to induce its siblings to refrain from negotiating or (2) it negotiates at a high level to induce its siblings to refrain from begging (Dreiss et al. 2010). By reducing investment in vocalizing in the absence of parents cort-individuals probably entailed the cost of not inducing their sibling to refrain from begging once parents are back at the nest. However, by behaving in this way cort-nestlings probably saved energy (Leech and Leonard 1996; Moreno-Rueda 2010; but see Bachman and Chappell 1998) to be reallocated into begging calls directed to the parents and to be able to spend more time closer to the nest-box entrance where parents delivered food in order to induce their siblings to refrain from negotiating.

Our findings differ from similar experiments carried out in nestling house sparrows (Loiseau et al. 2008). Sparrows treated with corticosterone increased their begging rate towards the parents but were unable to obtain as much food as their control siblings. Thus, in contrast to barn owl nestlings, house sparrows treated with corticosterone apparently behaved mal-adaptively because the increase in investment in sibling competition did not lead to a higher success in food obtaining. The discrepancy between our respective studies might be due to methodological differences. While we administrated corticosterone in barn owls within the natural physiological range (Müller et al. 2009), the dose used in sparrows was pharmacological. Kitaysky et al. (2001) also found that an experimental transient elevation of corticosterone induced black legged kittiwake (Rissa tridactyla) nestlings to exaggerate begging, which, in that case, resulted in an increase in food monopolization by $13 \%$. This means that in kittiwakes the higher costs of sibling competition induced by corticosterone were compensated by larger benefits. By contrast, in Nuttall's white-crowned sparrow (Zonotrichia leucophrys nuttalli) nestlings facing an acute transient elevation in corticosterone increased their latency to beg, hence potentially decreasing their feeding success (Wada and Breuner 2008). Clearly, more data are required in a larger range of species to evaluate the dose-dependent effect of corticosterone on sib-sib and parent-offspring interactions. This is necessary to determine under which situation and in which species corticosterone induces or reduces the costs and benefits of sibling competition.

Implications on the Evolution of Parent-Offspring and Sib-Sib Interactions

Our study was designed to investigate the role of corticosterone on sib-sib interactions and in turn on how food is shared among the progeny. Begging behavior can influence not only the within-brood food allocation (Smith and Montgomerie 1991; Whittingham et al. 2003; Rosivall et al. 2005; Porkert and Spinka 2006) but also parental overall feeding rates (e.g. Ottosson et al. 1997; Burford et al. 1998; Glassey and Forbes 2002). Unfortunately, our within-brood design did not allow us to examine whether an experimental increase in nestling corticosterone levels also influenced parental feeding rates. To examine this issue, all siblings should be implanted either with corticosterone- or placebo-pellets. This is important to consider because begging could be cooperative with siblings sharing investment in begging to a given threshold in order to ensure that parents quickly come back at the nest with food (Johnstone 2004). Hence, the question is whether corticosterone promotes or refrains siblings to behave cooperatively. Our observations on sibling negotiation, a form of cooperative behavior, suggest that corticosterone would rather refrain siblings to behave cooperatively even in species in which sibling negotiation does not occur. Thus, if only part of the nestlings are treated with corticosterone within a brood of several nestlings, these individuals may reduce investment in begging if solicitations by the placebo-siblings are sufficient to ensure higher parental feeding rate.

Our results may appear paradoxical since in spite of producing fewer negotiation calls cort-individuals reached the same success in monopolizing food as placebo-individuals. If the alternative strategy of cort-nestlings to stand closer to the nest entrance proved efficient in prey obtaining, why did placebo-individuals not behave in a similar way? A potential explanation is that standing close to the nest hole represents the most costly option with the non-negligible risk of falling out of the nest (Bize and Roulin 2006) a frequent outcome in the barn owl (pers. obs.). Additionally, reducing negotiation effort as in cortindividuals, may not be as rewarding as negotiating and may not be stable in the long-term. The primary function of sibling negotiation is to reduce the level of sibling competition, and thus reducing the level of negotiating would induce nestlings to become more aggressive among each other and to beg to higher levels; these costs may be higher than those induced by negotiation (Roulin 2002).

In conclusion, our results suggest that stressful factors that induce a transient rise in corticosterone levels may mainly promote the evolution of scramble competition rather than sibling negotiation and other forms of cooperation. Further experimental studies focusing on the adaptiveness of switching to physical competition in stressful situations would nonetheless be helpful to properly test this hypothesis. Manipulating corticosterone here rather than food need, as usually done in begging studies, thus demonstrates that diverse source of stress beyond food supply may have potent effects on the evolution of sib-sib vocal and physical interactions, and more generally on parentoffspring conflict. 
Acknowledgments The Swiss National Science Foundation supported the study financially (no. 3100A0_120517 to AR and no. 3100A0-104134 to LJ and SJE). We are grateful to Andreas Rieser, Sonja Braaker, Annick Morgenthaler, Ester Pellegrini, Sylvain Antoniazza, Silvan Rüttimann, Pascal König, Martin Amrein for their help in the field. We also thank three anonymous referees for helpful comments on an early version of the manuscript and Fränzi KornerNievergelt for statistical advice. The study was carried out with the authorization of the 'Service Vétérinaire du canton de Vaud'.

\section{References}

Almasi, B., Roulin, A., Jenni-Eiermann, S., Breuner, C. W., \& Jenni, L. (2009). Regulation of free corticosterone and CBG capacity under different environmental conditions in altricial nestlings. General and Comparative Endocrinology, 164(2-3), 117-124.

Bachman, G. C., \& Chappell, M. A. (1998). The energetic cost of begging behaviour in nestling house wrens. Animal Behaviour, $55,1607-1618$.

Bize, P., \& Roulin, A. (2006). Sibling competition and the risk of falling out of the nest. Animal Behaviour, 72, 539-544.

Blas, J., Baos, R., Bortolotti, G. R., Marchant, T. A., \& Hiraldo, F. (2006). Age-related variation in the adrenocortical response to stress in nestling white storks (Ciconia ciconia) supports the developmental hypothesis. General and Comparative Endocrinology, 148(2), 172-180.

Budden, A. E., \& Wright, J. (2005). Learning during competitive positioning in the nest: Do nestlings use ideal free 'foraging' tactics? Behavioral Ecology and Sociobiology, 58(3), 227-236.

Bulmer, E., Celis, P., \& Gil, D. (2008). Parent-absent begging: evidence for sibling honesty and cooperation in the spotless starling (Sturnus unicolor). Behavioral Ecology, 19(2), 279-284.

Burford, J. E., Friedrich, T. J., \& Yasukawa, K. (1998). Response to playback of nestling begging in the red-winged blackbird, Agelaius phoeniceus. Animal Behaviour, 56, 555-561.

Cotton, P. A., Kacelnik, A., \& Wright, J. (1996). Chick begging as a signal: Are nestlings honest? Behavioral Ecology, 7(2), 178-182.

Cotton, P. A., Wright, J., \& Kacelnik, A. (1999). Chick begging strategies in relation to brood hierarchies and hatching asynchrony. American Naturalist, 153(4), 412-420.

Creel, S. (2001). Social dominance and stress hormones. Trends in Ecology \& Evolution, 16(9), 491-497.

Dreiss, A., Lahlah, N., \& Roulin, A. (2010). How siblings adjust sibsib communication and begging signals to each other. Animal Behaviour, 80, 1049-1055.

Drummond, H. (2006). Dominance in vertebrate broods and litters. Quarterly Review of Biology, 81(1), 3-32.

Faraway, J. J. (2006). Extending the linear model with R. Boca Raton, FL.: Chapman and Hall, CRC.

Glassey, B., \& Forbes, S. (2002). Muting individual nestlings reduces parental foraging for the brood. Animal Behaviour, 63, 779-786.

Godfray, H. C. J. (1995a). Evolutionary-theory of parent-offspring conflict. Nature, 376(6536), 133-138.

Godfray, H. C. J. (1995b). Signaling of need between parents and young-parent-offspring conflict and sibling rivalry. American Naturalist, 146(1), 1-24.

Godfray, H. C. J., \& Parker, G. A. (1991). Clutch size, fecundity and parent offspring conflict. Philosophical Transactions of the Royal Society of London Series B-Biological Sciences, 332(1262), 67-79.

Grim, T. (2008). Wing-shaking and wing-patch as nestling begging strategies: Their importance and evolutionary origins. Journal of Ethology, 26(1), 9-15.
Johnstone, R. A. (2004). Begging and sibling competition: How should offspring respond to their rivals? American Naturalist, 163(3), 388-406.

Johnstone, R. A., \& Roulin, A. (2003). Sibling negotiation. Behavioral Ecology, 14(6), 780-786.

Kacelnik, A., Cotton, P. A., Stirling, L., \& Wright, J. (1995). Food allocation among nestling starlings-sibling competition and the scope of parental choice. Proceedings of the Royal Society of London Series B-Biological Sciences, 259(1356), 259-263.

Kilner, R. (1995). When do canary parents respond to nestling signals of need. Proceedings of the Royal Society of London Series B-Biological Sciences, 260(1359), 343-348.

Kitaysky, A. S., Piatt, J. F., Wingfield, J. C., \& Romano, M. (1999). The adrenocortical stress-response of Black-legged Kittiwake chicks in relation to dietary restrictions. Journal of Comparative Physiology B-Biochemical Systemic and Environmental Physiology, 169(4-5), 303-310.

Kitaysky, A. S., Wingfield, J. C., \& Piatt, J. F. (2001). Corticosterone facilitates begging and affects resource allocation in the blacklegged kittiwake. Behavioral Ecology, 12(5), 619-625.

Leech, S. M., \& Leonard, M. L. (1996). Is there an energetic cost to begging in nestling tree swallows (Tachycineta bicolor)? Proceedings of the Royal Society of London Series B-Biological Sciences, 263(1373), 983-987.

Leonard, M. L., Horn, A. G., \& Parks, E. (2003). The role of posturing and calling in the begging display of nestling birds. Behavioral Ecology and Sociobiology, 54(2), 188-193.

Lichtenstein, G., \& Sealy, S. G. (1998). Nestling competition, rather than supernormal stimulus, explains the success of parasitic brown-headed cowbird chicks in yellow warbler nests. Proceedings of the Royal Society of London Series B-Biological Sciences, 265(1392), 249-254.

Loiseau, C., Sorci, G., Dano, S., \& Chastel, O. (2008). Effects of experimental increase of corticosterone levels on begging behavior, immunity and parental provisioning rate in house sparrows. General and Comparative Endocrinology, 155(1), 101-108.

Love, O. P., Bird, D. M., \& Shutt, L. J. (2003). Plasma corticosterone in American kestrel siblings: Effects of age, hatching order, and hatching asynchrony. Hormones and Behavior, 43(4), 480-488.

McRae, S. B., Weatherhead, P. J., \& Montgomerie, R. (1993). American robin nestlings compete by jockeying for position. Behavioral Ecology and Sociobiology, 33(2), 101-106.

Moreno-Rueda, G. (2007). Is there empirical evidence for the cost of begging? Journal of Ethology, 25(3), 215-222.

Moreno-Rueda, G. (2010). An immunological cost of begging in house sparrow nestlings. Proceedings of the Royal Society B-Biological Sciences, 277(1690), 2083-2088.

Müller, C., Almasi, B., Roulin, A., Breuner, C. W., Jenni-Eiermann, S., \& Jenni, L. (2009). Effects of corticosterone pellets on baseline and stress-induced corticosterone and corticosteroidbinding-globulin. General and Comparative Endocrinology, 160(1), 59-66.

Müller, C., Jenni-Eiermann, S., \& Jenni, L. (2010). Development of the adrenocortical response to stress in Eurasian kestrel nestlings: Defence ability, age, brood hierarchy and condition. General and Comparative Endocrinology, 168, 474-483.

Munro, C., \& Stabenfeldt, G. (1984). Development of a microtitre plate enzyme-immunoassay for the determination of progesterone. Journal of Endocrinology, 101(1), 41-49.

Nunez-de la Mora, A., Drummond, H., \& Wingfield, J. C. (1996). Hormonal correlates of dominance and starvation-induced aggression in chicks of the blue-footed booby. Ethology, 102(5), 748-761.

Ostreiher, R. (2001). The importance of nestling location for obtaining food in open cup-nests. Behavioral Ecology and Sociobiology, 49(5), 340-347. 
Ottosson, U., Backman, J., \& Smith, H. G. (1997). Begging affects parental effort in the pied flycatcher, Ficedula hypoleuca. Behavioral Ecology and Sociobiology, 41(6), 381-384.

Ploger, B. J., \& Medeiros, M. J. (2004). Unequal food distribution among great egret Ardea alba nestlings: Parental choice or sibling aggression? Journal of Avian Biology, 35(5), 399-404.

Porkert, J., \& Spinka, M. (2006). Begging in common redstart nestlings: Scramble competition or signalling of need? Ethology, 112(4), 398-410.

Price, K. (1996). Begging as competition for food in Yellow-headed Blackbirds. Auk, 113(4), 963-967.

Py, I., Ducrest, A. L., Duvoisin, N., Fumagalli, L., \& Roulin, A. (2006). Ultraviolet reflectance in a melanin-based plumage trait is heritable. Evolutionary Ecology Research, 8(3), 483-491.

$\mathrm{R}$ Development Core Team. (2010). R: A language and environment for statistical computing. [2.12.1]. Vienna, Austria: R Foundation for Statistical Computing.

Rodriguez-Girones, M. A., Enquist, M., \& Lachmann, M. (2001a). Role of begging and sibling competition in foraging strategies of nestlings. Animal Behaviour, 61, 733-745.

Rodriguez-Girones, M. A., Zuniga, J. M., \& Redondo, T. (2001b). Effects of begging on growth rates of nestling chicks. Behavioral Ecology, 12(3), 269-274.

Romero, L. M., \& Reed, J. M. (2005). Collecting baseline corticosterone samples in the field: Is under $3 \mathrm{~min}$ good enough? Comparative Biochemistry and Physiology a-Molecular \& Integrative Physiology, 140(1), 73-79.

Rosivall, B., Torok, J., \& Szollosi, E. (2005). Food allocation in collared flycatcher (Ficedula albicollis) broods: Do rules change with the age of nestlings? Auk, 122(4), 1112-1122.

Roulin, A. (2001a). Food supply differentially affects sibling negotiation and competition in the barn owl (Tyto alba). Behavioral Ecology and Sociobiology, 49(6), 514-519.

Roulin, A. (2001b). On the cost of begging vocalization: Implications of vigilance. Behavioral Ecology, 12(4), 506-511.

Roulin A. (2002). The sibling negotiation hypothesis. In: J. Wright \& M. L. Leonard (Eds.), The evolution of begging (pp. 107-126). Dordrecht: Kluwer Academic Publishers.

Roulin, A. (2004). Effects of hatching asynchrony on sibling negotiation, begging, jostling for position and within-brood food allocation in the barn owl, Tyto alba. Evolutionary Ecology Research, 6(7), 1083-1098.

Roulin, A., Kolliker, M., \& Richner, H. (2000). Barn owl (Tyto alba) siblings vocally negotiate resources. Proceedings of the Royal Society of London Series B-Biological Sciences, 267(1442), 459-463.

Schwabl, H. (1999). Developmental changes and among-sibling variation of corticosterone levels in an altricial avian species. General and Comparative Endocrinology, 116(3), 403-408.

Schwabl H., Lipar J. (2002). Hormonal regulation of begging behaviour. In J. Wright \& M. Leonard (Eds.), The evolution of begging: Competition, cooperation and communication (pp. 221-244). Dordrecht: Kluwer Academic.

Smiseth, P. T., \& Amundsen, T. (2002). Senior and junior nestlings in asynchronous bluethroat broods differ in their effectiveness of begging. Evolutionary Ecology Research, 4(8), 1177-1189.

Smiseth, P. T., Bu, R. J., Eikenaes, A. K., \& Amundsen, T. (2003). Food limitation in asynchronous bluethroat broods: Effects on food distribution, nestling begging, and parental provisioning rules. Behavioral Ecology, 14(6), 793-801.

Smith, T. E., Leonard, M. L., \& Smith, B. D. (2005). Provisioning rules and chick competition in asynchronously hatching common terns (Sterna hirundo). Behavioral Ecology and Sociobiology, $58(5), 456-465$.

Smith, H. G., \& Montgomerie, R. (1991). Nestling American robins compete with siblings by begging. Behavioral Ecology and Sociobiology, 29(4), 307-312.

Sockman, K. W., \& Schwabl, H. (2001). Plasma corticosterone in nestling American kestrels: Effects of age, handling stress, yolk androgens, and body condition. General and Comparative Endocrinology, 122(2), 205-212.

Stier, K. S., Almasi, B., Gasparini, J., Piault, R., Roulin, A., \& Jenni, L. (2009). Effects of corticosterone on innate and humoral immune functions and oxidative stress in barn owl nestlings. Journal of Experimental Biology, 212(13), 2084-2090.

Tanner, M., Kolliker, M., \& Richner, H. (2008). Differential food allocation by male and female great tit, Parus major, parents: Are parents or offspring in control? Animal Behaviour, 75, $1563-1569$.

Teather, K. L. (1992). An experimental-study of competition for food between male and female nestlings of the red-winged blackbird. Behavioral Ecology and Sociobiology, 31(2), 81-87.

Trivers, R. L. (1974). Parent-offspring conflict. American Zoologist, 14(1), 249-264.

Vallarino, A., Wingfield, J. C., \& Drummond, H. (2006). Does extra corticosterone elicit increased begging and submissiveness in subordinate booby (Sula nebouxii) chicks? General and Comparative Endocrinology, 147(3), 297-303.

Wada, H., \& Breuner, C. W. (2008). Transient elevation of corticosterone alters begging behavior and growth of whitecrowned sparrow nestlings. Journal of Experimental Biology, 211(10), 1696-1703.

Whittingham, L. A., Dunn, P. O., \& Clotfelter, E. D. (2003). Parental allocation of food to nestling tree swallows: The influence of nestling behaviour, sex and paternity. Animal Behaviour, 65, 1203-1210.

Williams, C. T., Kitaysky, A. S., \& Buck, C. L. (2008). Food restricted Tufted Puffin (Fratercula cirrhata) nestlings increase vocal activity during handling without modulating total or free corticosterone. Journal of Ornithology, 149(2), 277-283. 